\title{
Multidimensional Analysis of Sao Paulo State (Brazil) Rural Development
}

\author{
Vinicius Palácio \\ School of Science and Engineering, Sao Paulo State University (UNESP), Av. Domingos da \\ Costa Lopes, 780, Tupa - SP, 17602-496, Brazil \\ E-mail: palacio.vinicius@hotmail.com
}

Wagner Luiz Lourenzani (Corresponding author)

School of Science and Engineering, Sao Paulo State University (UNESP), Av. Domingos da Costa Lopes, 780, Tupa - SP, 17602-496, Brazil

E-mail:w.lourenzani@unesp.br

Ferenc Istvan Bánkuti

Department of Animal Sciences, State University of Maringa (UEM), Av. Colombo, 5790, Maringa - PR, 87020-900, Brazil

E-mail: fibankuti@uem.br

Raquel Pereira de Souza

Agribusiness Engineering Department. Fluminense Federal University (UFF), Avenida dos Trabalhadores, 420, Volta Redonda - RJ, 27255-250, Brazil

E-mail: raquel.p.souza@gmail.com

Thiago Reis

School of Science and Engineering, Sao Paulo State University (UNESP), Av. Domingos da Costa Lopes, 780, Tupa - SP, 17602-496, Brazil

E-mail: thiago_reis@id.uff.br

Received: Feb. 11, 2020

doi:10.5296/jas.v8i3.16439
Accepted: Mar. 23, 2020 Published: Apr. 13, 2020

URL: https://doi.org/10.5296/jas.v8i3.16439 


\section{Abstract}

The objective of this study is to evaluate, through a multidimensional index, the level of rural development of the municipalities in the state of São Paulo, Brazil. The process used to determine the rural development factors, the contextualization of the dimensions, as well as the definition of the variables assigned to each one of them were carried out in order to accomplish this proposal. Thus, it was possible to elaborate and to analyze the mathematical index. Methodologically, we used Systematic Bibliographic Review, analytical exploration of the results, cluster analysis and Tukey test for index validation. Based on the analysis of the results it was possible to observe neighboring municipalities with similar results, which may justify not only the local evaluation but also a micro-regional or meso-regional study. The understanding of the quality of rural life of São Paulo, through a multidimensional index, was able to generate prior knowledge for development policies at regional and local scale.

Keywords: development index, rural development, multidimensional analysis

\section{Introduction}

Due to a number of factors, there are differences in establishing the "rural" concept. The reason may be related to time, space, both, and also related to definitions with strong ideological features. These factors are distorted over time by the varying objectives that are sought to be achieved with the definition, since they vary according to a scenario and a historical moment. For this reason, the United Nations itself addresses the rural definition as a key problem. "In rural development it is particularly important to have a clear understanding of what "rural" means and the geographical areas where it can be applied" (UN, 2007, p. 1).

According to the Brazilian Institute of Geography and Statistics (IBGE, 2017a), the definition of rural is everything that is not urban/urbanized. Legally, urban is the whole area of cities or towns, with streets and marked by constructions, and also the spaces affected by transformation or marked for urban development. However, according to Veiga (2002), such criteria may overestimate the real degree of national urbanization, which also does not evidence, or subjectively proves the rural territory. Thus, it is necessary to understand that the analysis of the rural environment is a complex object (Kageyama, 2004).

The rural environment has not always been seen as a space that supports the urban environment, or as a synonym of underdevelopment. It can be said that before everything was rural; however, with the development of society, urbanization, the various agricultural, industrial and technological revolutions and globalization, an opposition between the countryside and the city was created. Nowadays, the rural environment follows a new trend, characterized as a space that is not only food producer or synonymous with agricultural space, but also adding other aspects that culminate in its development, understood by the existence of rural-urban interrelationship and treated as a multidimensional space (Kageyama, 2008).

Rural multidimensionality carries within it a perspective of multifunctionality and multisectorality, with its development correlated to different conditioning factors (Kageyama, 2004). The definition of these conditioners goes through a set of spheres within various dimensions, which involve productive, environmental, social and economic aspects. These 
multidimensional conditioners can be treated mathematically in the form of an index, which can represent the rural development of a given space.

Indicators are decision-making tools, numerically representing behavioral phenomena and revealing broader meanings. That is, they serve as an instrumental basis for evaluating a specific framework, portraying in post-analysis the paths that are followed by the studied group through one or more specified variables.

For Kageyama (2004) and FAO/ISTAT (2011), an index must be robust and rigorous, and more precisely, consistent with what is being evaluated. For these authors, besides the empirical fact, the variables to be considered should be measurable and also express results that can be easily understood.

It is acknowledged that it is difficult to define the analysis space of the rural environment. In the case of a country such as Brazil, of continental dimensions and with a relative economic and social heterogeneity, such difficulty increases. For the feasibility of a scientific analysis, a geographical framework with relevant socioeconomic characteristics of the Brazilian rural area should be pursued.

Several studies have quantitatively evaluated the rural development in Brazil of both micro-regions and macro-regions. Specifically regarding the state of São Paulo, Kageyama (2004) evaluated the rural development of the municipalities of the state of São Paulo, based on a descriptive statistical approach based on data from the 95/96 Agricultural Census. Recent works such as Stege and Parré (2013), Bittencourt and Lima (2014), Begnini and Almeida (2016), Santos et al. (2017) and Souza (2019a), analyze rural development in different regions, with the same perspective of multidimensionality, but with a cluster analysis, which may present results closer to reality. Thus, considering the interstice of the evaluation based on the work of Kageyama (2004), and the new methodological approaches, it is considered scientifically relevant to (re)study the rural development of the municipalities in the state of São Paulo.

The most urban Brazilian state was chosen due to its diversity in the rural space and its socioeconomic importance. Data from the 2017 Agricultural Census (IBGE, 2017b) show that the state of São Paulo had 188 thousand rural establishments, of which $87 \%$ were smaller than 100 hectares. According to the 2006 Agricultural Census (IBGE, 2006) 66.3\% of all São Paulo rural establishments were classified as family farming. In addition, according to data from the 2017 Agricultural Census (IBGE, 2017b), 48\% of rural establishments in São Paulo develop their own activities at the establishment as their main source of income, and $52 \%$ of these establishments develop activities outside the establishment as their main source of income, which indicates the importance of non-agricultural activities in the composition of pluriactivity developed in the rural space of São Paulo.

In this context, it is significant to understand the rural space of a given region through a multidimensional index, in order to support decision makers and policy makers with information to propose effective actions for its development.

Therefore, the general objective proposed in this paper is to evaluate the level of rural 
development of the municipalities in the state of São Paulo. In order to achieve this objective, the following specific objectives have been determined: define the analysis dimensions that shape rural development; measure the variables that compose the different dimensions of the municipalities in the state of São Paulo; statistically evaluate the set of variables, creating explanatory factors/groups of rural development; and, finally, spatially analyze the results found.

\section{Material and Methods}

This work is based on the model proposed by Souza (2019a) and Kageyama (2008). According to this model, in which rural development is understood as a process (composed of stages or dimensions) and not as the end (Souza, 2019b). The model consists of three dimensions: i) the conditioning factors of rural development, from which indicators that characterize the demographic and economic basis are based on, under which the process of rural development is developed; ii) the characteristics of rural development, which include indicators that identify the socioeconomic and environmental characteristics of the development in question, that is, the paths that the development process follows; and iii) the effects or results of the development process, which are the indicators that expose the consequences (positive and negative) of the process in question.

Table 1 shows the structure of rural development analysis based on the dimensions, their conditioners and their respective variables.

Table 1. Variables that characterize the analysis dimensions and their data sources

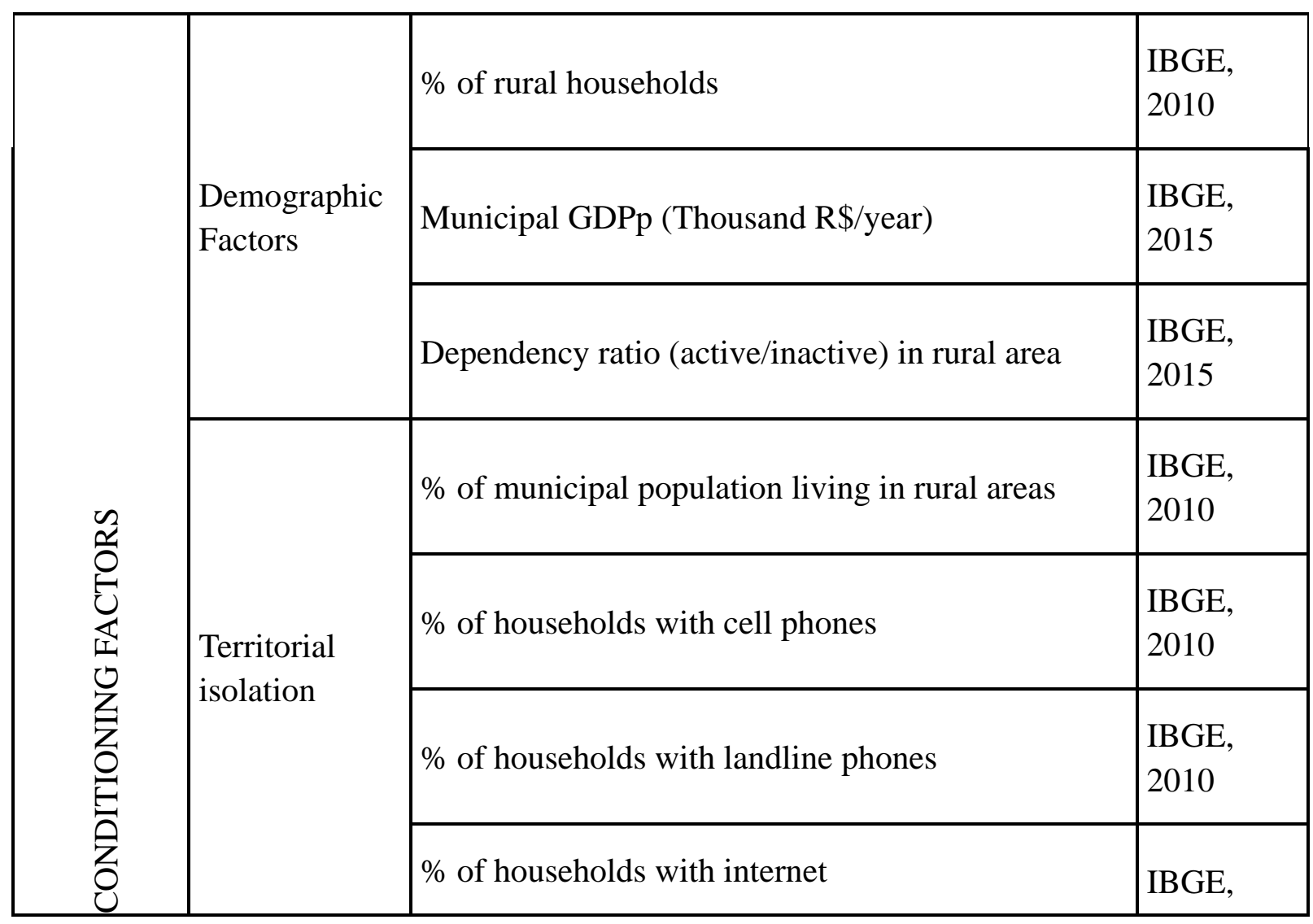




\begin{tabular}{|c|c|c|c|}
\hline & & & 2010 \\
\hline & & Demographic Density (hab/Km²) & $\begin{array}{l}\text { IBGE, } \\
2010\end{array}$ \\
\hline & \multirow{3}{*}{$\begin{array}{l}\text { Presence of } \\
\text { family } \\
\text { farming }\end{array}$} & $\%$ of planted area except for the two main crops & $\begin{array}{l}\text { IBGE, } \\
2010\end{array}$ \\
\hline & & $\%$ of production value from family farming & $\begin{array}{l}\text { IBGE, } \\
2010\end{array}$ \\
\hline & & Relation of cropland and other uses & $\begin{array}{l}\text { IBGE, } \\
2010\end{array}$ \\
\hline & \multirow{4}{*}{$\begin{array}{l}\text { Agricultural } \\
\text { Diversity }\end{array}$} & Ratio between planted and natural pastures & $\begin{array}{l}\text { IBGE, } \\
2010\end{array}$ \\
\hline & & Ratio of production value per area (ha) & $\begin{array}{l}\text { IBGE, } \\
2010\end{array}$ \\
\hline & & Production value per person employed in rural area & $\begin{array}{l}\text { IBGE, } \\
2010\end{array}$ \\
\hline & & $\begin{array}{l}\% \text { of area of rural establishments with woods and/or } \\
\text { forests }\end{array}$ & $\begin{array}{l}\text { IBGE, } \\
2006\end{array}$ \\
\hline \multirow{6}{*}{ 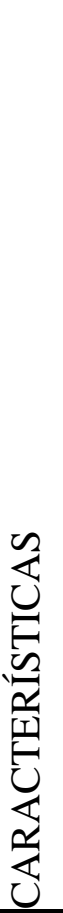 } & \multirow{5}{*}{ Environmental } & $\%$ of rural establishments that use level planting & $\begin{array}{l}\text { IBGE, } \\
2010\end{array}$ \\
\hline & & $\%$ of agricultural establishments that protect slopes & $\begin{array}{l}\text { IBGE, } \\
2010\end{array}$ \\
\hline & & $\%$ Family farmers who do not use pesticides & $\begin{array}{l}\text { IBGE, } \\
2010\end{array}$ \\
\hline & & $\%$ of agricultural establishments using crop rotation & $\begin{array}{l}\text { IBGE, } \\
2010\end{array}$ \\
\hline & & $\begin{array}{l}\% \text { of staff employed only in non-agricultural } \\
\text { activities in agricultural establishments }\end{array}$ & $\begin{array}{l}\text { IBGE, } \\
2010\end{array}$ \\
\hline & Pluriactivity & $\%$ of pluriactive agricultural establishments & IBGE, \\
\hline
\end{tabular}




\begin{tabular}{|c|c|c|c|}
\hline & & & 2010 \\
\hline \multirow{6}{*}{ 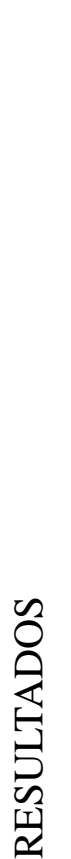 } & \multirow{2}{*}{ Schooling } & $\begin{array}{l}\text { Ratio of people aged } 15 \text { and over by people with } 8 \text { or } \\
\text { more years of study }\end{array}$ & $\begin{array}{l}\text { IBGE, } \\
2010\end{array}$ \\
\hline & & Literacy rate & $\begin{array}{l}\text { IBGE, } \\
2010\end{array}$ \\
\hline & \multirow{2}{*}{ Rural exodus } & Average of residents in rural households & $\begin{array}{l}\text { IBGE, } \\
2010\end{array}$ \\
\hline & & $\begin{array}{l}\text { Change }(\%) \text { of resident rural population between } \\
2000 \text { and } 2010\end{array}$ & $\begin{array}{l}\text { IBGE, } \\
2010\end{array}$ \\
\hline & \multirow{2}{*}{$\begin{array}{l}\text { Income and } \\
\text { poverty } \\
\text { reduction }\end{array}$} & $\%$ of farm establishment income from work & IPEA 2015 \\
\hline & & $\%$ of total value for family farming & IPEA 2015 \\
\hline
\end{tabular}

Source: Adapted from Souza (2019a).

This is a quantitative exploratory study, using secondary data obtained through documentary research. The main source for data collection was the IBGE Automatic Recovery System (SIDRA/IBGE) ${ }^{1}$. The units of analysis are the 645 municipalities of the state of São Paulo (Figure 1).

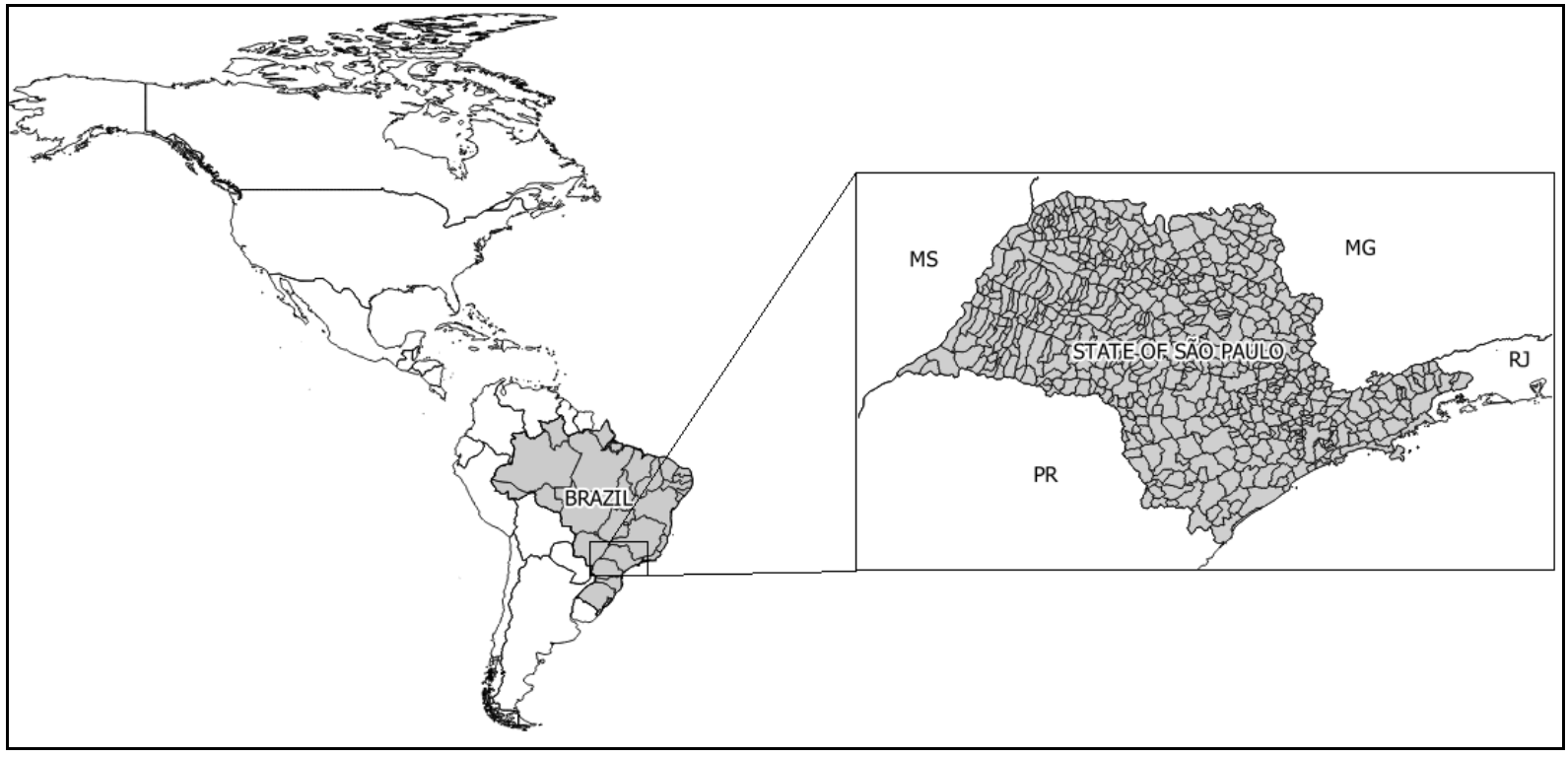

Figure 1. The municipalities of the state of São Paulo, Brazil

${ }^{1}$ https://sidra.ibge.gov.br/home/ipca15/brasil 
Source: Prepared by the authors

The first stage of analysis included systematizing the characteristic variables of each municipality in a database, categorized in their different dimensions. The first dimension (Conditioners) groups eleven variables into three subgroups: demographic factors, territorial isolation and the presence of family farming. The first measures aspects related to production and population dynamics. The second measures the distance between economic opportunities, favoring aspects such as diversification and social progress. The third subgroup measures the level of family farming, correlated with agricultural diversification, land decentralization and human occupation in the countryside (Kageyama, 2008; Souza, 2019a).

For Kageyama (2008), the "Characteristics" dimension constitutes the regional particularities, represented by the specific paths of each space. This set consists of ten variables, grouped into three subgroups: agricultural diversity, environmental characteristics and pluriactivity. According to Souza (2019a), the first subgroup measures the intensification of agriculture, since greater diversity and high productivity is the way to raise the level of rural development. The environmental subgroup consists of the characteristic variables about the current state of agriculture and the exploitation of rural space, based on the assumption that agricultural diversity combined with the preservation of protected spaces determines the elevation of the state of development.

The "Results" dimension evaluates the characteristics that represent well-being and quality of life through education, income and population movement. It is made up of three subgroups: education, rural exodus, and income and poverty reduction. There are several studies that include education as a promoter of development (Melo and Parré, 2007; Bittencourt and Lima, 2014; Santos et al., 2017). The rural exodus, a characteristic factor in the 1960s, is still relevant due to the difficulties of the countryside and the promise of a better life in urban centers. According to Souza (2019a), rural development implies a reduction in population movement since it establishes a dignified life in the countryside with environmental respect.

These variables were standardized based on the collected variables, where the highest value was 1 and the lowest 0 . This procedure allowed analyzing and interpreting the results, in a simple manner, without losing information. Then, the average value of the variables of each dimensional set was calculated. Thus, each municipality of the state of São Paulo received an average value in the three dimensions - Conditioners, Characteristics and Results.

Based on the average values of each municipality, for each of the dimensions, the Hierarchical Cluster Analysis (HCA) technique was applied. This clustering method seeks, on the one hand, to minimize variability within sets and, on the other, to maximize variability between sets. It is an algorithm that starts a process with only one set and performs iterations, looking for the best result that meets the two aforementioned objectives, and creating representative sets of data (Metz, 2006).

It is an approach that builds groups by similarity. Unlike other approaches, the result of the hierarchical method does not result from data partition, but is done by a distant hierarchy between the analyzed levels (Metz, 2006). 
It is noteworthy that the adopted analysis model establishes the clusters by the distance between the mean values, in this case, for each municipality of the state of São Paulo. Such classifications are performed according to the internal results of each dimension, exclusively conducted for the municipalities evaluated. Thus, a given average can be categorized as high in one dimension but low in another.

In addition, not all 645 municipalities in the state of São Paulo were classified in representative clusters. Those municipalities that did not present similar characteristics with some cluster were considered outliers and were therefore not classified (Hair et al., 2010). For some municipalities no information was found on the variables analyzed.

The groups of municipalities were analyzed and compared with each other, based on the variables that defined them - dimensions. To that end, the Analysis of Variance - ANOVA was used as procedure. The difference between the mean values of each dimension between the groups was assessed by the Tukey test $(\mathrm{p}<0.05)$. This assessment allowed the groups to be classified, in each dimension, into three levels: (1) High, (2) Medium, and (3) Low (Bánkuti and Caldas, 2018).

To generate the rural development index (RDI) of each municipality, a categorization was established based on their classification in the three dimensions (Conditioners/Characteristics/Results). To this end, the following rule was followed:

- Very High RDI: High/High/High or High/High/Medium;

- High RDI: High/High/Low or High/Medium/Medium;

- Medium RDI: Medium/Medium/Medium or High/Medium/Low;

- Low RDI: Medium/Medium/Low or High/Low/Low;

- Very Low RDI: Low/Low/Medium or Low/Low/Low;

- No Classification: outliers.

Based on the identification of the RDIs of the municipalities, the results were spatialized. The spatialization of municipalities based on the indicators generated has been constantly used to assist in the interpretation of rural production and development indices (Bánkuti and Caldas, 2018; Melo and Parré, 2007). Through a Geographic Information System (GIS), and with the QGIS software (Quantum GIS) v. 2.81, thematic maps of the three analyzed dimensions were constructed, as well as the Rural Development Index of the municipalities of the state of São Paulo. The Geographic Information System (GIS) and the QGIS software (Quantum GIS) v. 2.81, were used to build thematic maps of the three analyzed dimensions, as well as the Rural Development Index of the municipalities of the State of São Paulo.

\section{Results Analysis}

Based on the database with all the variables of the municipalities, of the different analysis dimensions, the cluster analysis was performed by the hierarchical method, and the results of these groups are presented in Table 2. 
In the "Conditioners" dimension, 595 municipalities were classified into three groups (low, medium and high) (Table 2). Thus, 50 municipalities were considered outliers. The main factors that led to the declassification of these municipalities were the low percentage of rural households and, consequently, the population residing in the rural area, as well as the low valuation of the variables that characterized the presence of family farming. Municipalities with a high monoculture index were also declassified. The averages of these groups showed a relatively similar dispersion. The "low" and "medium" groups represented approximately $82 \%$ of the entire sample.

The "Characteristics" dimension obtained the largest number of classified municipalities 637, and only 8 municipalities were considered outliers. Variations in averages were also relatively similar, and in total approximately $93 \%$ of municipalities were grouped into the "medium" and "low" clusters (Table 2).

The last dimension, "Result", classified 632 municipalities in its three groups, 13 of which were considered outliers. The average values found were higher than the other dimensions. The group in the "low" and "medium" clusters represented approximately $87 \%$ of the municipalities (Table 2).

Table 2. Cluster analysis result classified by the level of the analyzed dimension

\begin{tabular}{|c|c|c|c|c|c|}
\hline DIMENSIONS & GROUPS & $\mathbf{N}$ & PERCENTAGE & AVERAGE & $\begin{array}{l}\text { STANDARD } \\
\text { DEVIATION }\end{array}$ \\
\hline \multirow{4}{*}{ 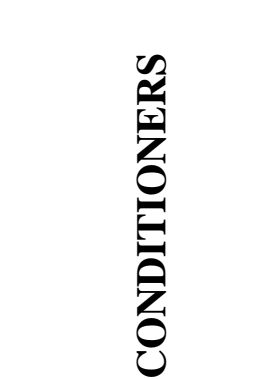 } & LOW & 138 & $23 \%$ & 0.2062 & 0.014 \\
\hline & AVERAGE & 352 & $59 \%$ & 0.2568 & 0.0185 \\
\hline & HIGH & 105 & $18 \%$ & 0.323 & 0.0212 \\
\hline & TOTAL & 595 & $100 \%$ & 0.2568 & 0.0412 \\
\hline \multirow{4}{*}{ 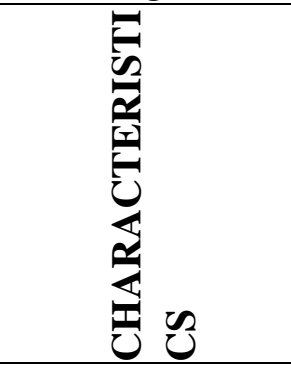 } & LOW & 348 & $55 \%$ & 0.1055 & 0.0199 \\
\hline & AVERAGE & 242 & $38 \%$ & 0.162 & 0.015 \\
\hline & $\mathrm{HIGH}$ & 47 & $7 \%$ & 0.2073 & 0.0114 \\
\hline & TOTAL & 637 & $100 \%$ & 0.1345 & 0.038 \\
\hline \multirow{4}{*}{ 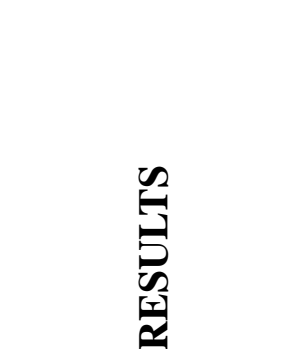 } & LOW & 204 & $32 \%$ & 0.3507 & 0.02504 \\
\hline & AVERAGE & 347 & $55 \%$ & 0.4107 & 0.0163 \\
\hline & HIGH & 81 & $13 \%$ & 0.4732 & 0.0213 \\
\hline & TOTAL & 632 & $100 \%$ & 0.3993 & 0.0448 \\
\hline
\end{tabular}

Source: Prepared by the authors. 


\section{Macrothink}

Journal of Agricultural Studies

ISSN 2166-0379

2020, Vol. 8, No. 3

It was found that the standard deviations of all groups of the different dimensions were very consistent, presenting low coefficients of variation and denoting a good internal framework (Table 2).

Then, the question was to confirm whether the different groups (high, medium and low) identified by the cluster analysis had statistical differences between them. This verification was to verify the similarity of the municipalities in the same group and their difference in relation to the other groups. Table 3 presents these results, with each group compared to the others, within the same dimension.

The results were positive for differences in all clusters by the Tukey test, since the evaluated sigma was less than 0.05 (Table 3). Thus, it can be stated that this data set is representative to analyze and compare its results with an index composed of all results.

Table 3. Analysis of variance between groups

$\begin{array}{llll}\text { Conditioners } & \text { Average } & \text { Conditioners Average } & \text { Average } \\ \text { Variables } & \text { Variables } & \text { difference } & \text { Standard Error Sig. } \\ \text { (I) } & (\mathrm{J}) & (\mathrm{I}-\mathrm{J}) & \end{array}$

\begin{tabular}{|c|c|c|c|c|}
\hline \multicolumn{5}{|c|}{ Dependent Variable: AVERAGE CONDITIONING FACTORS } \\
\hline \multirow{2}{*}{ LOW } & AVERAGE & $-.05062^{*}$ & 0.00182 & 0.000 \\
\hline & HIGH & $-.11677^{*}$ & 0.00202 & 0.000 \\
\hline \multirow{2}{*}{ AVERAGE } & LOW & $.05062^{*}$ & 0.00182 & 0.000 \\
\hline & HIGH & $-.06616^{*}$ & 0.00235 & 0.000 \\
\hline \multirow{2}{*}{ HIGH } & LOW & $-.11677^{*}$ & 0.00232 & 0.000 \\
\hline & AVERAGE & $-.06616^{*}$ & 0.00202 & 0.000 \\
\hline
\end{tabular}

Dependent Variable: AVERAGE CHARACTERISTICS

\begin{tabular}{lllll}
\hline \multirow{2}{*}{ LOW } & AVERAGE & $-.05646^{*}$ & 0.001480824 & 0.000 \\
& HIGH & $-.1018^{*}$ & 0.002749381 & 0.000 \\
\hline \multirow{2}{*}{ AVERAGE } & LOW & $.05646^{*}$ & 0.001480824 & 0.000 \\
& HIGH & $-.0453^{*}$ & 0.002820117 & 0.000 \\
\hline \multirow{2}{*}{ HIGH } & LOW & $.1018^{*}$ & 0.002749381 & 0.000 \\
& AVERAGE & $.0453^{*}$ & 0.002820117 & 0.000 \\
\hline \multirow{2}{*}{ Dependent Variable: AVERAGE RESULTS } & & & \\
\hline \multirow{2}{*}{ LOW } & AVERAGE & $-1.0807^{*}$ & 0.114570462 & 0,000 \\
& HIGH & $-2.2425^{*}$ & 0.122771505 & 0,000 \\
\hline \multirow{2}{*}{ AVERAGE } & LOW & $1.0807^{*}$ & 0.050577424 & 0,000 \\
& HIGH & $1.0807^{*}$ & 0.122771505 & 0,000 \\
\hline \multirow{2}{*}{ HIGH } & LOW & $2.2425^{*}$ & 0.050577424 & 0,000 \\
& MEDIO & $1.1617^{*}$ & 0.114570462 & 0,000 \\
\hline
\end{tabular}




\section{MIMacrothink}

* Different column means ( $\mathrm{p}<0.05)$ by Tukey test.

Source: Prepared by the authors, SPSS software 22.2.

After the statistical analysis, the cluster spatialization was performed for each of the analyzed dimensions. Figure 2 shows, in the form of a map, the clusters identified in the "Conditioners" dimension. Its categorization involved eleven variables and, according to Kageyama (2008), this dimension represents the basis for the rural development index.

Most of the municipalities (352 or 55\%) were categorized as having a "medium" level of rural development conditioning factors, which are scattered throughout the state of São Paulo (Figure 2). These are the municipalities that presented the homogeneous measurements of the variables close to those of the state averages, which belonged to the subgroups demographic factors, territorial isolation and presence of family agriculture.

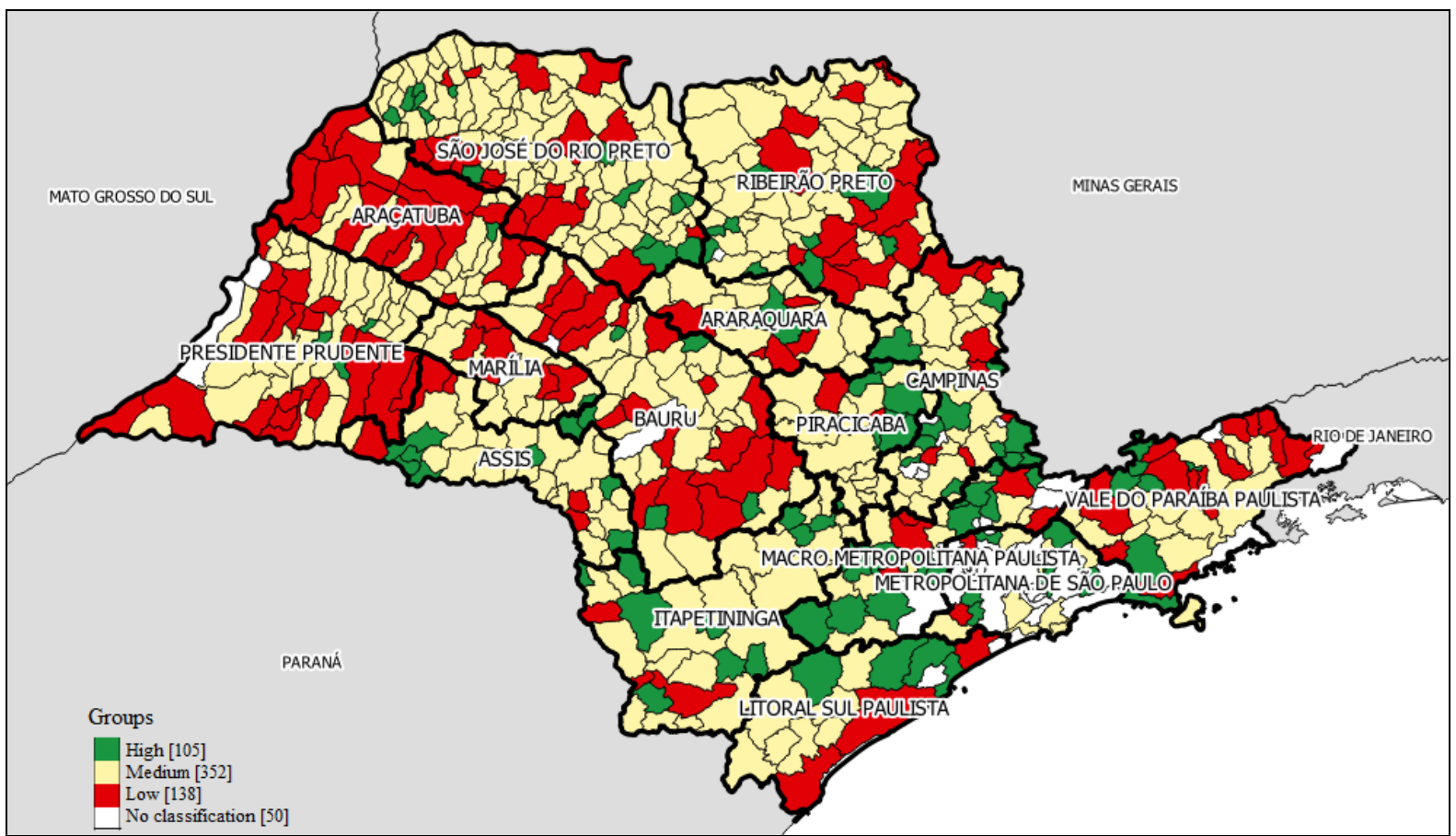

Figure 2. Classification of the "Conditioning Factors" dimension groups

Source: Prepared by the authors, IBGE 2018 digital mesh, original SIDRA data, QGIS 2.81 software

Those levels categorized as "low" made up 21\% (138) of the municipalities analyzed (Table 2). Municipalities in this group were those with the lowest conditioning factors for rural development when compared to other municipalities in the state, especially in the percentage of rural households and in the proportion of establishments with less than 50 ha. It may be, therefore, that these municipalities have, compared to the rest of the state, the worst social and economic bases on which a virtuous rural development process is developed. In general, there were agglomerations of these municipalities in the central-eastern state, especially in the Araçatuba, Presidente Prudente, Bauru and Marília meso-regions (Figure 2). It is noteworthy that the western region in the state of São Paulo was one of the last to be 


\section{MInstitute ${ }_{\text {Int" }}^{\text {Macrothink }}$}

colonized.

The "high" level municipalities accounted for $16 \%$ of the sample. These municipalities presented the highest averages among the subgroup variables, and are predominantly located in the south-central region, such as the Piracicaba, Campinas and Metropolitana Paulista regions (Figure 2), the oldest and most populous regions of the state. It is these regions that have, in comparison with the rest of the state, the best social and economic bases on which a virtuous rural development process can be developed.

Based on this spatial analysis, it can be assumed that the level of conditioning factors for rural development may be directly related to the development trajectory of the regions and their proximity to larger consumer centers.

Figure 3 shows the spatialization of the "Characteristics" dimension. It analyzes the differences in the trajectories that determined the characteristics or trajectories of rural development, thus assuming the path of diversified productive activity, the path of environmental preservation or the path of pluriactivity (KAGEYAMA, 2008). Thus, levels (low, medium, high) are associated with the intensity of exploration of these different trajectories. Municipalities rated as high level, compared to the others, can have more of these different trajectories in their rural development processes compared to the low level ones, which can have less trajectory opportunities for their development process.

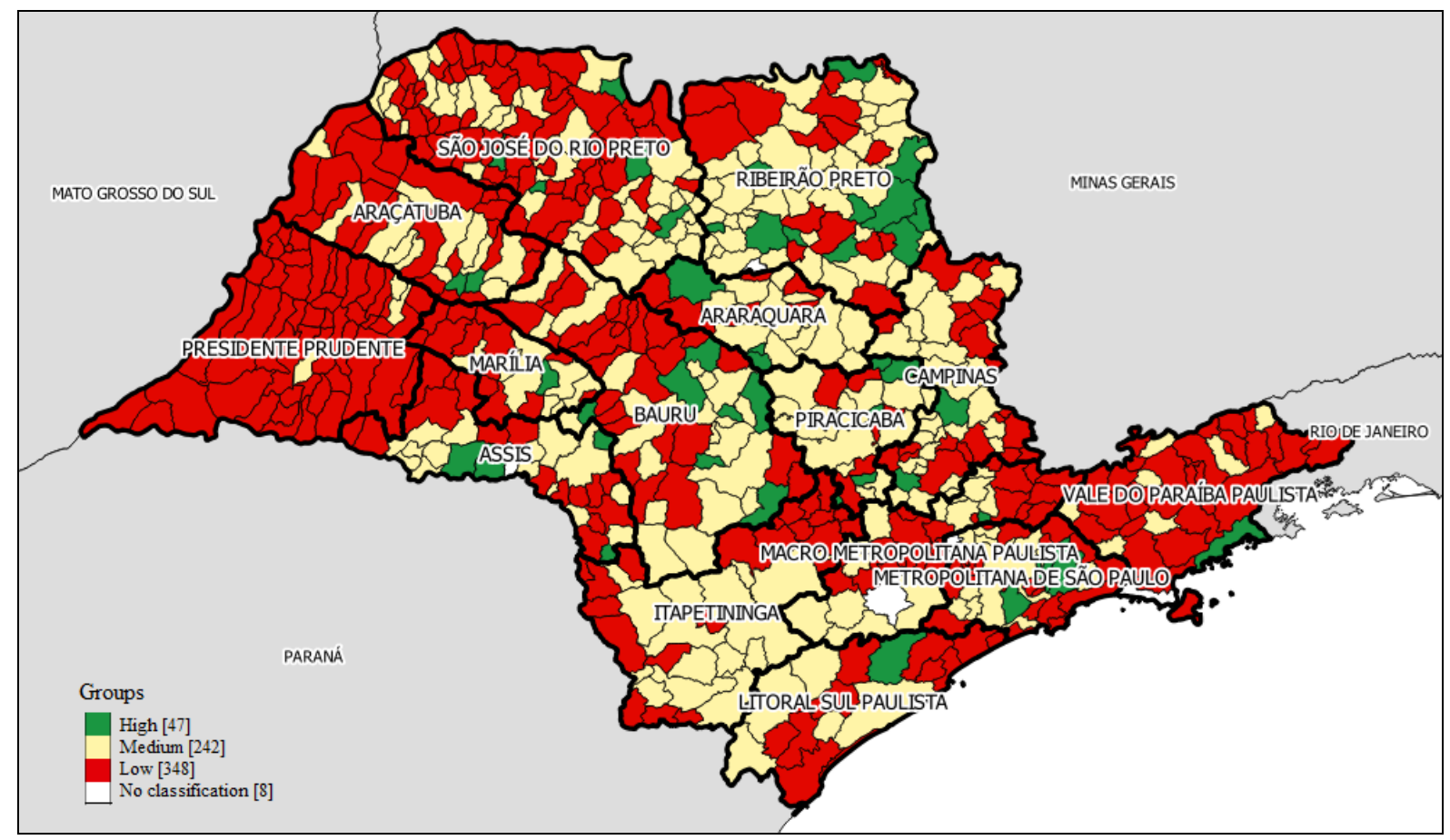

Figure 3. Classification of the "Characteristics" dimension groups

Source: Prepared by the authors, IBGE 2018 digital mesh, original SIDRA data, QGIS 2.81 software

In this dimension, the largest group of municipalities (348 or 54\%) was classified as "low" (Table 2). Both the Midwest and East regions of the state had the largest agglomerations of 


\section{Macrothink}

these municipalities (Figure 3). It was found that $94 \%$ of the municipalities of the Presidente Prudente Meso-region and $80 \%$ of the Vale do Paraíba Meso-region are in this group. For these municipalities, the averages of all variables of the analyzed subgroups were below the state averages.

The central region of the state contains most of the municipalities classified as "medium" and "high" (Figure 3). Those at the "medium" level totaled 38\% of the municipalities (Table 2). The "high" level represented only $7 \%$ of the sample (Table 2), highlighting the production value indicators per employed person and the pluriactivity index of the establishments, which denotes the importance of productive diversity and pluriactivity as the main trajectories used for the levels of development achieved in these regions.

Figure 4 shows the clusters of the "Results" dimension. This dimension classified 632 cities in terms of economic and social results for the populations involved. The largest group of municipalities of this dimension was classified as "medium" (54\%), which is distributed throughout the state (Table 2 and Figure 4).

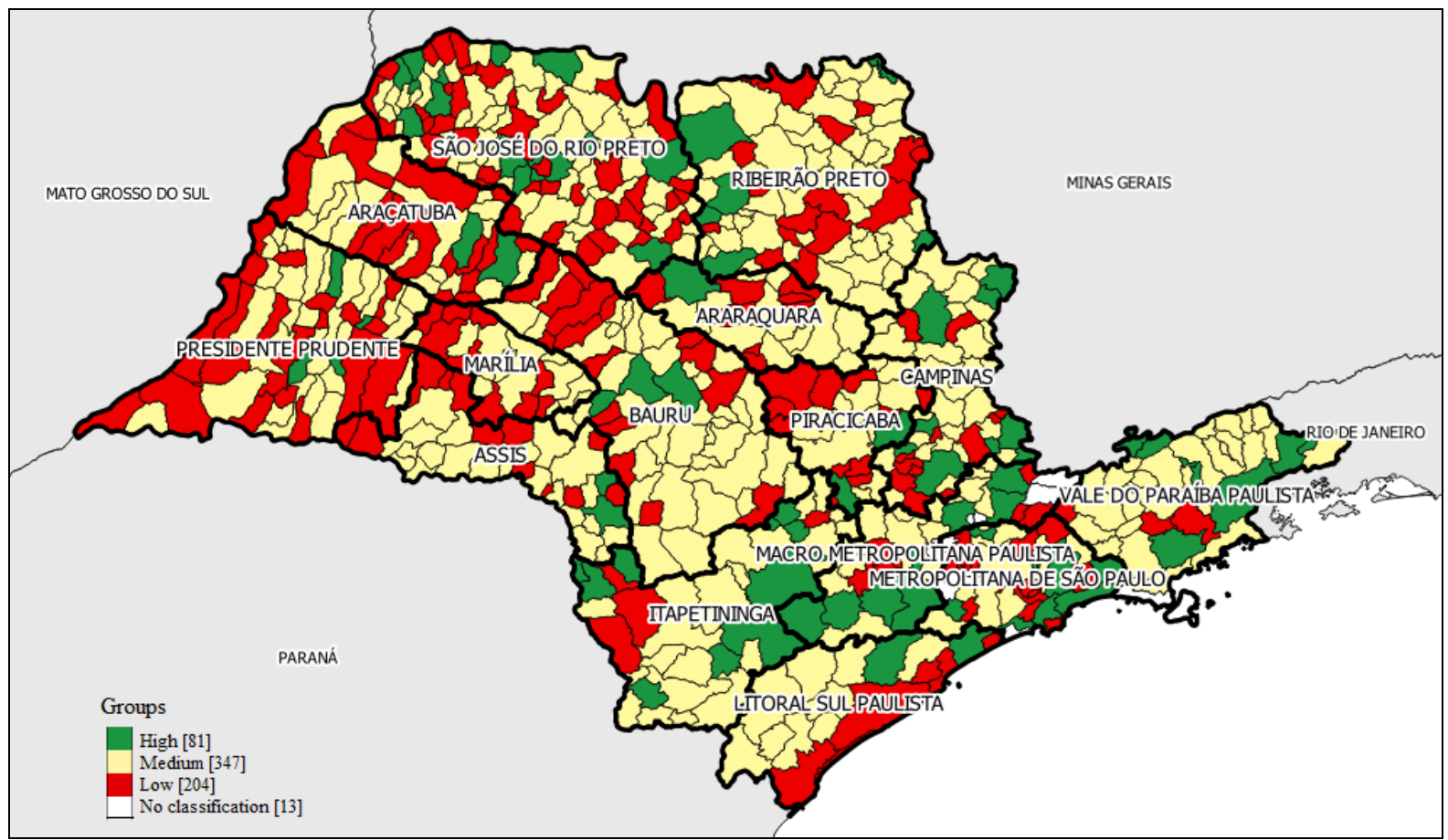

Figure 4. Classification of the "Results" dimension clusters

Source: Prepared by the authors, IBGE 2018 digital mesh, original SIDRA data, QGIS 2.81 software

The other clusters, "low" (204 or 32\%) and "high" (81 or 12\%) (Table 2), also presented a spatial dispersion throughout the state, with a slight concentration of the Midwest for the municipalities with lower factors level, and the Southeast region with the highest municipalities (Figure 4).

The prevailing variables for the discrimination between these two groups of municipalities were the income percentage from work establishments and the number of people living in 


\section{MInstitute Macrothink $_{\text {Int }}$}

rural areas for more than 15 years. In this context, in those municipalities where the rural population is predominantly older, with mostly retirement income, the "Results" dimension is low. To a lesser extent, the literacy rate of the municipalities also contributed to this classification.

Based on the three classified dimensions, it was possible to establish the degree of rural development for each of the municipalities by applying the categorization rule presented in the methodology of this work. Six categories were adopted, one of which refers to the group of "not classified" municipalities (57 or 9\%), which consisted of those which did not have any classification in any of the three dimensions analyzed.

Thus, in total, 588 municipalities were classified as: Very Low RDI (154 or 24\%), Low RDI (186 or $29 \%$ ), Medium RDI (154 or $24 \%$ ), High RDI (74 or 11\%) and Very High RDI (20 or $3 \%$ ). The map of this spatialization is represented by Figure 5.

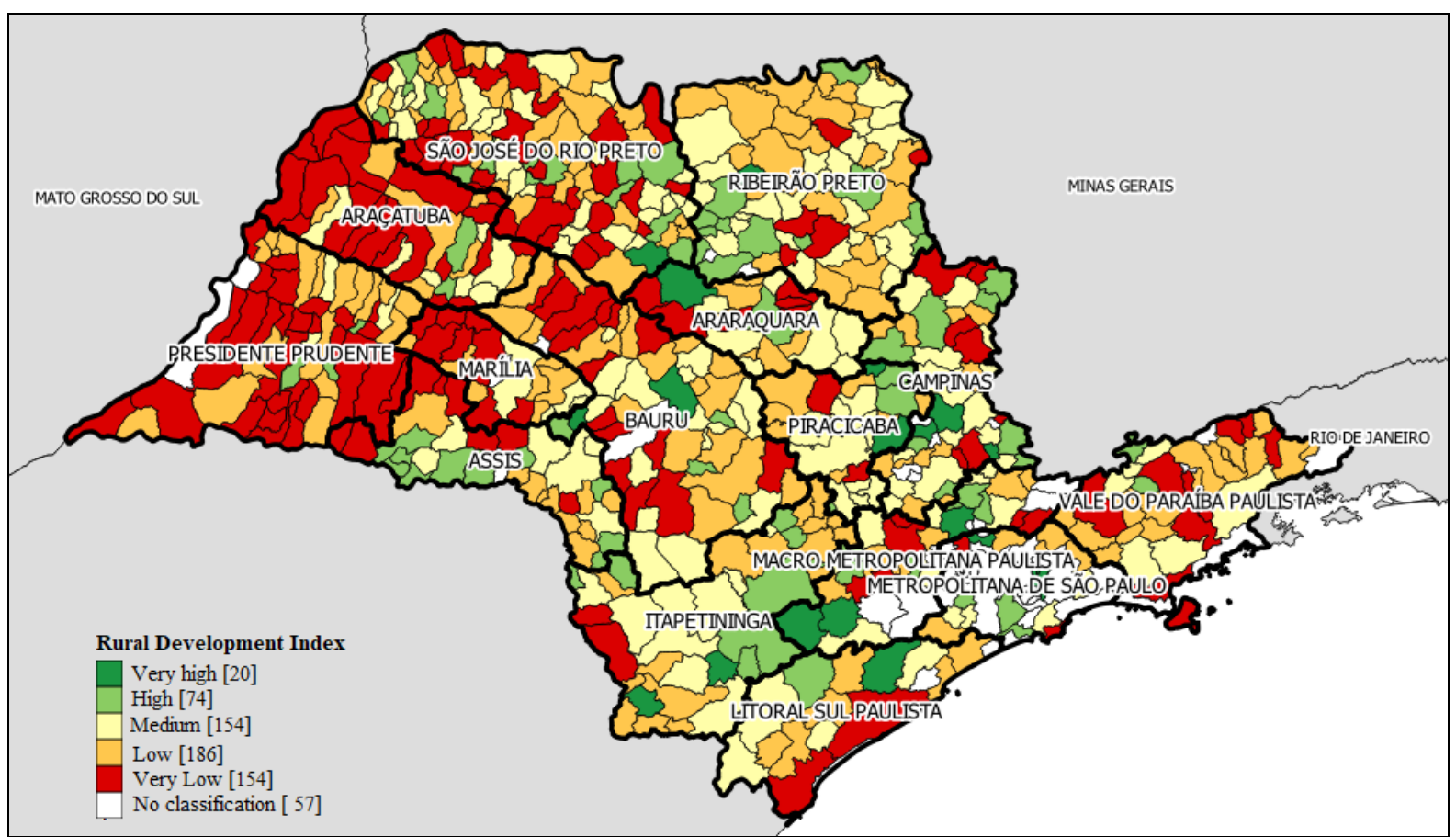

Figure 5. Rural Development Index for the municipalities of São Paulo

Source: Prepared by the authors, IBGE 2018 digital mesh, original SIDRA data, QGIS software 2.81

As observed in the classifications dimension, the group of municipalities with "high" classification was the smallest (Table 2). Consequently, this result was reflected in the rural development index, and only $14 \%$ of the total of the municipalities of São Paulo were classified in the two largest groups ("very high" and "high"). At the other extreme, however, more than half of the municipalities (53\%) were grouped as having a "low" or "very low" level of rural development. This situation shows the need for effective actions and measures, with emphasis on public policies, allowing municipalities to rise in the different dimensions of rural development. 
In regional terms, some good-result clusters are observed at the intersections of different Meso-regions, such as "Ribeirão Preto/São José do Rio Preto/Araraquara", "Campinas/Piracicaba", "Itapetininga/Metropolitana" (Figure 5). These clusters have the characteristic of surrounding large urban centers.

Within the scope of municipalities, those considered as regional poles, only Araraquara and Itapetininga are in the "high" and "very high" cluster (Figure 5). Interestingly, the other poles are mostly classified as "low" and "medium" RDI. This shows that, although important, the presence of the consumer market alone is not sufficient to provide rural development. For this to happen, issues that actually translate into better conditions for its inhabitants need to be reconfigured.

\section{Conclusion}

By achieving the aim of understanding the level of rural development of the municipalities of São Paulo, this study highlights some points. The first ones refer to the geographical framework used, since being the state with the largest national economy, it is possible that its rural space presents different characteristics from other regions of the country. It was based on this perspective that the comparative analysis of the municipalities was performed within an intrastate framework.

Thus, understanding the complexity of the rural environment, at any evaluation scale, is already a step towards providing information necessary for the development of actions for its development. For this reason, it is understood that, although equivalent factors are analyzed for all São Paulo municipalities, they are different from each other, with different socioeconomic characteristics and their regional characteristics.

Thus, variables that represented the comprehensive macro concept in question were adopted, which is rural development, from a multidimensional perspective, and that surpassed the analysis only for economic purpose.

The construction of the index proved to be an unbiased modeling and interpretation endeavor. In this context, this work elaborated, systematized and analyzed the level of rural development of the municipalities of São Paulo, under a multidimensional approach, disclosing different levels of clusters.

The metropolitan region of São Paulo was the most representative agglomeration of an unclassified portion. This fact is clearly due to the high level of urbanization of these regions, nullifying most of the variables adopted in this research.

The results showed that approximately $85 \%$ of the municipalities of São Paulo are in the medium, low and very low levels of rural development, which indicates the need for efforts, which must be implemented into effective development actions. Twenty-four percent of the municipalities of São Paulo were classified at the "very low" level, which reveals a worrying fragility, especially in the western part of the state.

Despite the obvious heterogeneity of the state, there are clusters of neighboring municipalities with the same level of rural development. This result allows transposing the 
analysis of rural development from the municipal to the (micro) regional level. Thus, it appears that the possibility (or responsibility) that the dedication of multidimensional efforts to pursue rural development goes beyond the boundary of the municipality, and worked at the regional level. From this perspective, the commitment of collective actions of regional scope can provide results that a municipality alone could not achieve.

Finally, a limiting point in the research is the difficulty of finding updated data of the different variables adopted, highlighting the problem of generating and disseminating official information in the country. However, notwithstanding the conclusions obtained, it is possible to understand how the state in fact needs attention from a multidimensional perspective for the rural environment, understanding that such environment is totally dependent on the urban environment, and vice versa.

\section{References}

Bánkuti, F. I., \& Caldas, M. M. (2018). Geographical milk redistribution in Paraná State, Brazil: consequences of institutional and market changes. Journal of Rural Studies, 64, 63-72. https://doi.org/10.1016/j.jrurstud.2018.10.004

Begnini, S., \& Almeida, L. E. D. F. (2016). Rural development in the State of Santa Catarina, Brazil: a multidimensional study. Revista Gestão \& Regionalidade, 32(94), 20-35. https://doi.org/10.13037/gr.vol32n94.3149

Bittencourt, G. M., \& Lima, J. E. (2014). Profile of rural development of municipalities of mesoregion the Mining Triangle and High Paranaiba. Revista Gestão \& Regionalidade, 30(89), 4-19. https://doi.org/10.13037/gr.vol30n89.1824

FAO/ISTAT - Food and Agriculture Organization/ Istituto Nazionale di Statistica. (2011). Statistics on rural development and agricultural household income. Wye City Group, Rome. https://ebiblio.istat.it/digibib/Agricoltura/IST0001668Statistics_on_rural_development_and_a griculture_household_income.pdf

Hair, J. F., Black, W. C., Babin, B. J., \& Anderson, R. E. (2010). Multivariate data analysis: international version. Pearson, New Jersey.

IBGE - Brazilian Institute of Geography and Statistics. (2006). 2006 Agricultural Census. http://www.sidra.ibge.gov.br

IBGE - Brazilian Institute of Geography and Statistics. (2010). 2010 Demographic Census. https://censo2010.ibge.gov.br/

IBGE - Brazilian Institute of Geography and Statistics. (2017a). Classificação $e$ caracterização dos espaços rurais e urbanos do Brasil: uma primeira aproximação. IBGE, Rio de Janeiro. https://biblioteca.ibge.gov.br/visualizacao/livros/liv100643.pdf

IBGE - Brazilian Institute of Geography and Statistics. (2017b). 2017 Agricultural Census. https://censos.ibge.gov.br/agro/2017/

IBGE - Brazilian Institute of Geography and Statistics. (2018). Geosciences . IBGE, Rio de 
Janeiro. https://www.ibge.gov.br/en/geosciences/downloads-geosciences.html

Kageyama, A. (2004). Rural development: concept and measurement. Cadernos de Ciência \& Tecnologia, 21(3), 379-408.

Kageyama, A. (2008). Desenvolvimento rural: conceitos e aplicações ao caso brasileiro. Editora da UFRGS, Porto Alegre.

Melo, C. O., \& Parré, J. L. (2007). Rural development index of the municipalities of Paraná: determining factors and hierarchization. Revista de Economia e Sociologia Rural, 45(2). 329-365. https://doi.org/10.1590/S0103-20032007000200005

Metz, J. (2006). Interpretation of clusters generated by hierarchical clustering algorithms. Dissertation (Master in Mathematical Sciences) of Graduate Program in Computer and Mathematical Sciences, University of São Paulo (USP), São Carlos, 152 p.

Santos, L. F., Ferreira, M. A. M., \& Salgado, R. J. S. F. (2017). Rural development of municipalities in Minas Gerais, Brazil: determining factors and hierarchization. Revista Gestão \& Regionalidade, 33(97), 83-99. https://doi.org/10.13037/gr.vol33n97.3640

Souza, R. P. (2019a). Rural development in Rio de Janeiro State from a multidimensional analysis. Revista de Economia e Sociologia Rural, 57(1), 109-126. https://doi.org/10.1590/1234-56781806-94790570107

Souza, R. P. (2019b). Indicators of rural development: achievements for a municipal analysis proposal. Revista Brasileira de Gestão e Desenvolvimento Regional, 15(2), 120-128.

Stege, A. L., \& Parré, J. L. (2013). Developpement rural des microrégions du Brésil: une étude multidimensionnelle. Confins (Paris) 19, 8640. https://doi.org/10.4000/confins.8640

UN - United Nations. (2007). Indicators of sustainable development: framework and methodologies. United Nations, New https://www.un.org/esa/sustdev/natlinfo/indicators/guidelines.pdf

Veiga, J. E. (2002). Cidades imaginárias: o Brasil é menos urbano do que se calcula. Autores Associados, Campinas.

\section{Copyright Disclaimer}

Copyright for this article is retained by the author(s), with first publication rights granted to the journal.

This is an open-access article distributed under the terms and conditions of the Creative Commons Attribution license (http://creativecommons.org/licenses/by/4.0/). 